\title{
TESTICULAR CHONDROSARCOMA
}

\author{
ULVIYE YALÇINKAYA, GÜLAYDAN FILIZ \\ Department of Surgical Pathology, Uludað University Medical School, Bursa, Turkey
}

\begin{abstract}
A case of primary chondrosarcoma of the testis is reported. A 40-year-old man presented a painless swelling of the right testis that he has been observing for 3 years. Gross examination of the resected specimen showed an encapsulated, gray to tan colored, roughly rounded tumor. Histologically, the tumor revealed a well-differentiated chondrosarcoma.
\end{abstract}

Key words: testis; testiculat neoplasms; chondrosarcoma

Int Braz J Urol. 2003; 29: 522-523

\section{INTRODUCTION}

Although extra-skeletal cartilaginous neoplasms are rare, chondroid differentiation of teratomatous tumors of the testis is common. Benign cartilaginous component can be found in about $75 \%$ of mature teratomas and $54 \%$ of malignant teratomas of the testis. Primary intratesticular chondrosarcoma is extremely rare. We report a case of a testicular chondrosarcoma.

\section{CASE REPORT}

A 40-year-old man was admitted to the hospital with a painless mass in the right scrotum. The mass had been present for 3 years. The left testis was normal. There was no history of trauma to the testis or any other significant previous illness, such as mumps or venereal disease. Physical examination revealed an otherwise healthy man. A biopsy of the mass was performed and a diagnosis of testicular malignant neoplasm was made. A right orchiectomy was performed.

\section{Pathologic Findings}

Gross examination of the resected specimen showed a well-defined, translucent, gray to tan col- ored, stone-hard, lobulated tumor measuring $13 \times 10$ x $8 \mathrm{~cm}$ with a spermatic cord with normal appearance attached to it (Figure-1). Tumor weighed 480 grams and was firm. Microscopic examination of the tumor revealed typical features of a well differentiated chondrosarcoma. The cross sections of the tumor exposed irregularly shaped lobules of cartilage of various sizes and shapes. The lobules were separated by fibrous connective tissue. Nuclear irregularity and increased cellularity were seen. There were 1 or 2 tumor cells with one or more hyperchromatic plump nuclei per lacuna (Figure-2). Mitotic figures were rare, and necrosis was not seen. Positive immunoreactivity for S-100 in the cytoplasms of the tumor cells was found.

\section{COMMENTS}

Although primary malignant mesenchymal tumors of the testis are rare, chondroid differentiation of teratomatous tumor of the testis is not. Five percent of all teratomas of the testis are well differentiated, and nearly $75 \%$ of these tumors contain cartilage elements. Pure cartilaginous tumors of the testis are extremely rare (1). In literature, Dounis described a chondroma (2) and Fuzesi et al. reported a metastasizing primary testicular chondrosarcoma (3). 


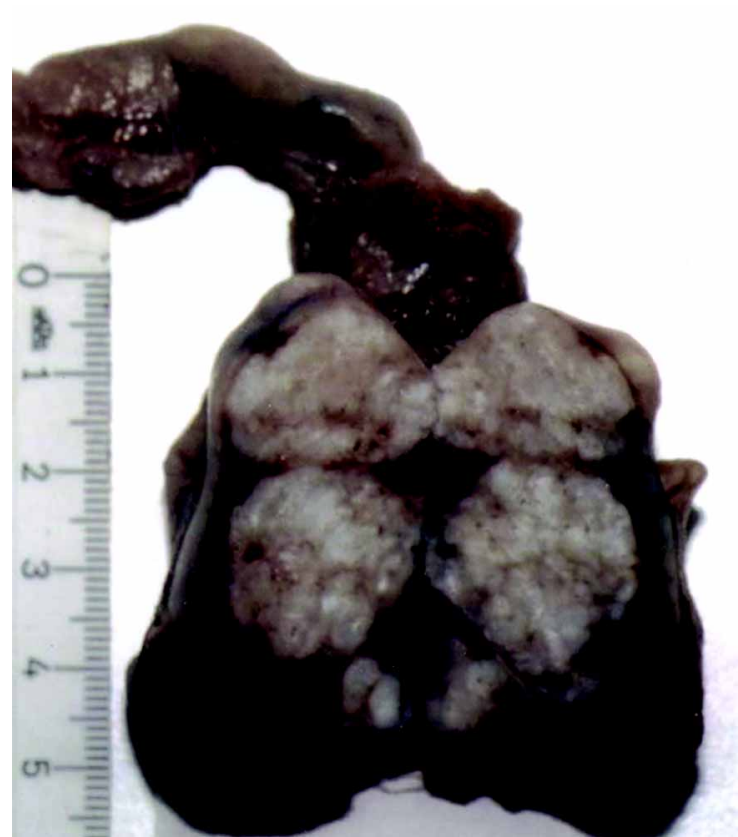

Figure 1 - Orchiectomy specimen longitudinally opened, demonstrating lobulated tumoral tissue.

The former case was reported to be fit and well with no evidence of metastasis 2 years after definitive surgery, and the latter was reported to be in remission 36 months after surgery. The present case is the second testicular chondrosarcoma reported in English literature, and likewise the formerly reported case, the patient is well 25 months afteroperation.

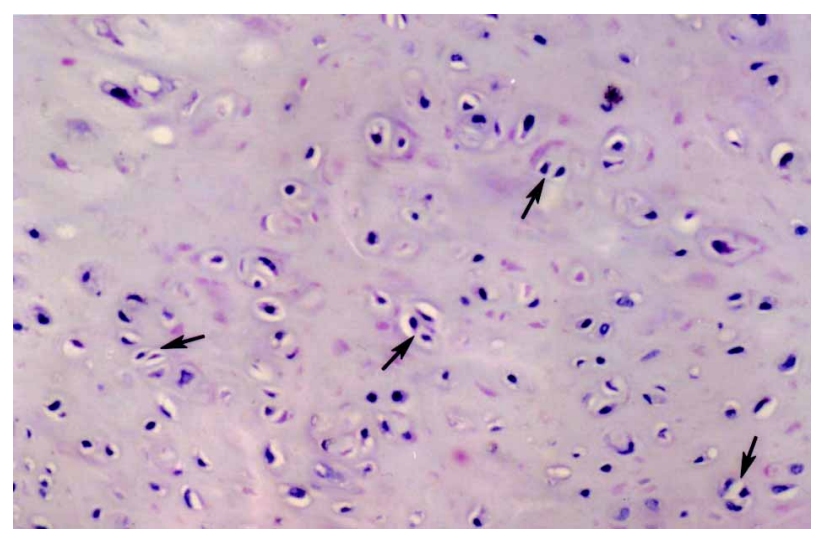

Figure 2 - Hypercellularity and more than 1 plump nuclei in lacunae (black arrows) (HE, X200).

\section{REFERENCES}

1. Washecka RM, Mariani AJ, Zuna RE, Honda SA, Chong CD: Primary intratesticular sarcoma. Immunohistochemical ultrastructural and DNA flow cytometric study of three cases with e review of the literature. Cancer. 1996; 77: 1524-8.

2. Dounis A: Primary chondroma of testis. Br J Urol. 1984; 56: 334-5.

3. Fuzesi L, Rixen H, Kirschner-Hermans R: Cytogenetic findings in a metastasizing primary testicular chondrosarcoma. Am J Surg Pathol. 1993; 17: 738-42.

Received: October 24, 2002 Accepted after revision: October 20, 2003

\section{Correspondence address:}

Dr. Ulviye Yalçýnkaya

Department of Surgical Pathology

Uludað University Medical School

Bursa 16059, Turkey

Fax: + 90224 442-8038

E-mail: u_yalcinkaya@yahoo.com 